\title{
A divergência entre Otto Wagner e Gottfried Semper: uma questão de detalhes
}

João Quintela

joaopedroquintela@gmail.com

Escuela Técnica Superior de Arquitecura - Universidad Politécnica de Madrid, CEACT/UAL -

Centro de Estudos de Arquitetura, Cidade e Território da Universidade Autónoma de Lisboa |

Invited Auxiliary of Da/UAL | Architect

Para citação: Quintela, João - A divergência entre Otto Wagner e Gottfried Semper: uma questão de detalhes. Estudo Prévio 17. Lisboa: CEACT/UAL - Centro de Estudos de Arquitetura, Cidade e Território da Universidade Autónoma de Lisboa, 2020. ISSN: 2182-4339 [Disponível em: www.estudoprevio.net]. DOI: https://doi.org/10.26619/2182-4339/17.03

Artigo recebido a 25 de junho de 2020 e aceite para publicação a 17 julho de 2020 . Creative Commons, licença CC BY-4.0: https://creativecommons.org/licenses/by/4.0/

\section{Resumo}

As origens do conceito de tectónica na arquitetura moderna situam-se no final do século XIX através das figuras de Karl Bötticher (Nordhausen, 1806 - Berlim, 1889) e Gottfried Semper (Hamburgo, 1803 - Roma, 1879). Numa entrevista recente o arquiteto Kenneth Frampton (Woking, 1930- ), que dedicou grande parte da sua investigação a este tema (1983, 1990, 1995, 2005) promovendo o entendimento da tectónica como "potencial de expressão construtiva", destacou um momento particular no qual Otto Wagner (Viena, 1841 - Viena, 1918) se declara dececionado com o seu mestre Gottfried Semper por ter abandonado a primazia pela estrutura e pela expressão construtiva. Para Wagner a forma artística só poderia ser concebida a partir da construção, o que o coloca muito mais próximo da formulação teórica de Karl Bötticher.

Este artigo estuda a evolução do conceito de tectónica na transição do Séc. XIX para o Séc. $\mathrm{XX}$ analisando as divergências entre o pensamento do teórico alemão Gottfried Semper, e o pensamento de Otto Wagner registado no seu livro "Moderne Architektur: seinen Schülern ein Führer auf diesem Kunstgebiete" (1896), tendo como foco a análise do edifício Postal Savings Bank (Viena, 1905). Neste projeto Wagner põe em prática as suas reflexões teóricas a partir de um detalhe construtivo capaz de relacionar a forma núcleo com a forma artística, dois conceitos que continuam a ter uma possível aplicabilidade prática na arquitetura contemporânea.

Palavras-Chave: Otto Wagner, Gottfried Semper, Kenneth Frampton, forma artística, forma núcleo, tectónica 


\section{Introdução}

"O homem moderno não precisa de vestimentas para servir de máscara. A sua individualidade tornou-se tão forte que já não precisa de exprimi-la através do vestuário. A ausência de ornamentação é um sinal de força intelectual. O homem moderno utiliza o ornamento de culturas antigas e desconhecidas a seu bel-prazer e como bem entende, e concentra a sua própria criatividade noutras coisas." (Loos, 2004)

É com estas palavras que em 1908 o arquiteto Adolf Loos (Brno, 1870 - Viena 1933) termina o texto Ornamento e Delito, seguramente uma das suas reflexões teóricas mais relevantes, com repercussões ainda nos dias de hoje. Escrito num tom tão irónico quanto acutilante, o artigo viria a ser publicado na língua original apenas em 1929, pelo jornal de Frankfurt, tendo sido até essa data difundido em praticamente todas as línguas (Loos, 2004: 234).

Num momento em que a produção arquitetónica contemporânea se vê confrontada com um regresso ao ornamento nas suas múltiplas abordagens, e sobretudo como caminho para alcançar a expressão formal e simbólica do objeto arquitetónico, parece inevitável olhar de novo para o contexto teórico e prático do final do século XIX, nomeadamente o debate em torno do ornamento e da sua relação com a estrutura e o sistema construtivo. Para tal, recorremos à figura de Otto Wagner e em particular às suas reflexões teóricas, onde podemos identificar algumas críticas a Gottfried Semper. Estas considerações viriam a ser materializadas de forma mais explícita no edifício do Postal Savings Bank, construído em Viena entre 1904 e 1906. O tratamento da fachada deste edifício revela uma mudança significativa em relação às suas primeiras obras e representa o culminar de uma investigação que tinha sido explorada de forma gradual em algumas obras precedentes. Neste projeto existe uma vontade inequívoca em clarificar a noção de "forma artística" e "forma núcleo", e sobretudo o modo como a articulação entre ambos poderia ser a expressão de uma arquitetura própria do seu tempo (Wagner, 1993). A forma artística estaria relacionada com o ornamento e a carga simbólica do edifício, enquanto a forma núcleo estaria vinculada com a estrutura e a construção.

\section{2. 'Moderne Architektur': reconhecimento e crítica a Gottfried Semper}

Um dos fatores decisivos para a importância de Otto Wagner na história da arquitetura foi o facto de ter levado a cabo uma obra teórica de charneira que acabaria por clarificar o debate em torno da correta apropriação dos estilos, que durava há várias décadas, e estabelecer um conjunto de premissas para o nascimento da arquitetura moderna dos anos seguintes (Wagner, 1993).

"Foi o primeiro texto moderno a fazer uma rutura definitiva com o passado, propondo uma abordagem ao projeto que acabou por se tornar habitual no século XX. No entanto, do ponto de vista histórico talvez seja mais correto ver o seu trabalho como o culminar dos esforços do século XIX para a criação de um novo estilo" (Mallgrave, 1988:1). 
permitiram um melhor entendimento da sua obra e contribuíram para uma herança arquitetónica. A forte influência que teve nos estudantes da Academia de Belas Artes de Viena deu origem à famosa Wagnerschule que daria a conhecer alguns dos seus discípulos e ex-colaboradores como Josef Hoffmann (Brtnice, 1870 - Viena, 1956), Joseph Maria Olbrich (Opava, 1867 - Düsseldorf, 1908), Josef Plečnik (Ljubljana, 1872 - Ljubljana, 1957) ou Max Fabiani (Komen, 1865 - Gorizia, 1962) que deram continuidade a uma investigação acerca das novas condições técnicas e plásticas da arquitetura e o modo como estas poderiam dar origem a um novo estilo arquitetónico que, neste caso concreto, acabaria por se refletir sobretudo no tratamento da fachada e no carácter simbólico da superfície.

O livro foi publicado pela primeira vez no ano de 1896 e reeditado novamente por mais três vezes em 1898, 1902 e 1914, sempre sob a cuidadosa revisão do seu autor. Para além dos prefácios que produziu para cada uma das edições, Wagner foi introduzindo alterações a diferentes níveis, desde a substituição de pequenas palavras ou introdução de novos capítulos, até à substituição do título original já na última edição para Die Baukunst unserer Zeit (Arquitetura do nosso Tempo). Vários autores se dedicaram a analisar as diferenças entre as quatro publicações oficiais uma vez que nos permitem perceber melhor a evolução do pensamento de Wagner e as correspondências com a sua obra construída (Mallgrave, 1988). Um dos aspetos poucas vezes referidos e que, no entanto, parecem relevantes para o tema que queremos analisar, prende-se com as alusões ao seu mestre Gottfried Semper.

Se analisarmos as várias edições em retrospetiva verificamos que há pequenas alterações ou esclarecimentos introduzidos por Wagner que nos dão algumas pistas. Conforme constata Henry Mallgrave "na edição de 1898, Wagner exclui o adjetivo da frase 'o desenho imortal de Semper' (edição de 1896), expondo assim o declínio da popularidade de Semper por volta de 1900" (Mallgrave, 1988: X). Este aparente distanciamento em relação a Semper foi também sublinhado por Kenneth Frampton numa entrevista recente onde refere que o livro "contém uma crítica em relação a Gottfried Semper porque, do ponto de vista de Wagner, Semper não foi capaz de manter a importância em relação à estrutura." (Frampton, 2020)

Se analisarmos a primeira versão de Moderne Architektur encontramos referências positivas a Semper, algumas das quais são suprimidas nas revisões posteriores. Um dos exemplos acontece logo no primeiro capítulo, que discorre sobre o papel do arquiteto e no qual Wagner refere que

"Hans Makart tinha maior aptidão inata do que conhecimento adquirido, enquanto no caso de Gottfried Semper aconteceu o contrário. No caso dos arquitetos, devido à enorme quantidade de material de estudo que deve ser assimilado, prevalece a relação entre as duas capacidades, idêntica à de Semper" (Wagner, 1993: 35).

Este parágrafo viria a ser retirado em 1914, na mesma altura em que Wagner amplia a edição original com dois novos capítulos intitulados $A$ promoção da arte e $A$ crítica da arte. Aqui podemos encontrar uma crítica ao projeto de Semper para o Teatro Nacional de Viena no qual, segundo Wagner, alguns elementos se encontram desproporcionados em relação ao conjunto e o foyer poligonal constitui uma "deceção estética" (Wagner, 1993: 144). 
$\overline{\mathrm{E}}$, no entanto, no quarto capítulo de Moderne Architektur onde encontramos os três momentos chave que os nos ajudam a compreender a afirmação anterior de Kenneth Frampton. Este capítulo tem como título "A construção" e é visto por muitos como o ponto central de toda a obra teórica de Wagner (Mallgrave, 1988: 29). É aqui que antecipa alguns temas arquitetónicos que irá explorar poucos anos mais tarde em alguns edifícios de carácter urbano e que culminará na sua obra mais emblemática, o Postal Savings Bank. Não será casual o facto de ser precisamente aqui que Wagner deixa por escrito os maiores elogios, mas também as maiores críticas em relação a Semper.

O primeiro momento acontece logo na primeira página. Wagner afirma que:

"necessidade, propósito, construção e idealismo constituem, portanto, a semente da vida arquitetónica. Unidos num único conceito, eles formam uma espécie de elemento 'indispensável' na génese e na existência de qualquer obra de arte; é este o significado do aforismo: artis sola domina necessitas. Alguém tão experiente como Gottfried Semper dirigiu pela primeira vez a nossa atenção em relação à certeza deste postulado (embora, infelizmente, também ele se tenha afastado rapidamente dele) e, desse modo, tenha indicado claramente o caminho que devemos seguir." (Wagner, 1993: 77).

Wagner reconhece a importância de Semper por ter aberto caminho para as novas gerações, no entanto não deixa de criticar a sua incapacidade para levar a cabo o seu projeto teórico.

Esta ideia volta a ser aprofundada num segundo momento, um pouco mais à frente, quando Wagner afirma:

"é um mérito indiscutível de Semper ter chamado a nossa atenção para este postulado [através do seu livro Der Stil], escrito de uma maneira um pouco exótica. Mas, tal como Darwin, não teve a coragem necessária para completar as suas teorias e confiou no caráter simbólico da construção, em vez de considerar a própria construção como a célula primitiva da arquitetura" (Wagner, 1993: 80).

Wagner estava definitivamente convencido de que a construção, em si mesma, teria de ser o ponto de partida para a conceção de qualquer arquitetura e não a sua representação simbólica, como teria sido apontado por Semper. Wagner esclarece em seguida que "a construção vem sempre em primeiro lugar, porque sem ela nenhuma forma artística poderá surgir, e o objetivo da arte, que é idealizar o existente, torna-se impossível sem a existência prévia do objeto" (Wagner, 1993: 81).

Já na parte final deste capítulo encontramos a terceira referência a Semper, num conjunto de reflexões dedicadas aos métodos de construção sólidos de rápida execução, próprios da arquitetura moderna e que deveriam ser utilizados de forma correta. Wagner começa por defender que o arquiteto tem duas tarefas essenciais. Deve apresentar as formas artísticas com grande claridade construtiva e, simultaneamente, demonstrar às pessoas que essas mesmas formas artísticas se expressam de maneira correta em função dos materiais utilizados, caso contrário haveria sempre "um certo grau de embuste ou de inquietação" (Wagner, 1993: 84).

Ao falar destes métodos construtivos, nomeadamente as suas vantagens económicas e qualidades expressivas, Wagner analisa um exemplo concreto que apenas na última 
revisão do livro, em 1914, identifica como sendo o Teatro Nacional de Viena projetado por Gottfried Semper e Karl von Hasenauer (Viena, 1833 - Viena, 1894). Segundo Wagner a utilização da pedra neste edifício representava um excessivo gasto de tempo e de dinheiro e, como tal, tratava-se de "uma maneira de construir que devemos definir como errónea" (Wagner, 1993: 85). Em seguida, para validar o seu argumento, Wagner apresenta um exemplo da maneira de construção moderna e embora não faça referência a nenhum dos seus projetos descreve exatamente a solução de revestimento com placas de pedra que ele próprio desenvolveu e aplicou em muitos dos seus edifícios: "estas placas podem ter uma espessura muito menor e, em troca, podem ser de um material mais nobre (por exemplo, mármore de Laas). A fixação de estas placas poderia realizar-se através de um sistema de ancoragem em bronze (rosetas)." (Wagner, 1993: 85). A concluir esta comparação entre ambos os exemplos, Wagner declara que esta segunda opção reduziria a cubicagem da pedra em cerca de um quinto em relação ao projeto de Semper no entanto o efeito monumental seria bastante superior devido à utilização de um material mais nobre num período de construção mais curto.

\section{Segundo Kenneth Frampton a razão do descontentamento de Wagner}

"deve-se ao neoclassicismo da arquitectura de Semper, em particular quando vai para Viena e trabalha em colaboração com Karl von Hasenauer (...) é uma espécie de neoclassicismo tardio que Semper já tinha utilizado na Opera de Dresden quando fez os seus primeiros trabalhos para a corte. Mas a coisa mais importante aqui é o facto de Wagner expressar o seu desapontamento com Semper porque Wagner está realmente preocupado com a expressão da estrutura. Claro que também existe ornamento em Wagner, mas se pensarmos no Postal Savings Bank, um dos seus trabalhos mais importantes, o revestimento de pedra está fixo com metal e Wagner tenta expressar a estrutura essencial desses elementos."

Esta afirmação leva-nos a confirmar que o ponto de divergência de Wagner em relação a Semper está precisamente no entendimento dos conceitos de forma núcleo e forma artística, e sobretudo na prevalência de um sobre o outro. Para Wagner não há dúvida que "o arquiteto deve desenvolver sempre a forma artística a partir da construção" (Wagner, 1993: 81) e isso expressa-se em primeira instância na fachada exterior do edifício.

\section{A construção da forma artística no Postal Savings Bank}

A arquitetura vienense na transição do século XIX para o século $X X$ revela uma atenção particular quanto ao tratamento da fachada dos edifícios. Num momento de transformações sociopolíticas e tecnológicas este elemento de transição entre o espaço público e o espaço privado era visto como uma manifestação cultural e ideológica no desenho da cidade o que lhe conferia um caráter simbólico de extrema relevância. A superfície de revestimento revelava o caráter do edifico da mesma forma que a indumentaria denunciava o status de uma pessoa na sociedade. Este entendimento da superfície como metáfora do ato de vestir (Bekleidung) decorria das interpretações diretas dos escritos de Gottfried Semper e em particular da importância 
atribuída à arte têxtil no livro "Der Stil in den technischen und tektonischen Künsten oder praktische Ästhetik: Ein Handbuch für Techniker, Künstler und Kunstfreunde" (1860).

Contudo, se analisarmos as obras de Otto Wagner, Josef Hoffman, Max Fabiani ou Josef Plečnik verificamos que a interpretação da teoria do revestimento de Semper foi bastante distinta entre os arquitetos vieneses. Os dois casos mais paradigmáticos para entendermos estas diferenças são o Palais Stoclet (Bruxelas, 1911), de Josef Hoffman, e o Postal Savings Bank (Viena, 1906), de Otto Wagner, que em seguida analisaremos com maior detalhe. Eduard Sekler classificou o Palais Stoclet como "atectónico" por revelar um grau de abstração tal que todos os detalhes convocam a negação da construção em prol da sublimação da forma (Sekler, 1967). Essa vontade de anular a expressão construtiva é evidente sobretudo se analisarmos a esquina do edifício onde os dois planos exteriores se encontram. No ponto de contacto entre estas duas superfícies revestidas por placas de mármore perfeitamente complanares, Hoffmann insere um elemento metálico preto e dourado, semelhante a um rebordo têxtil, que se prologa por todas as arestas. O ornamento, neste caso a forma artística, aparece aqui para anular a junta construtiva e esconder a espessura da placa de mármore, negando assim qualquer possibilidade de expressão tectónica suscetível de revelar tanto a técnica construtiva quanto a lógica estrutural (Figuras 1 e 2).

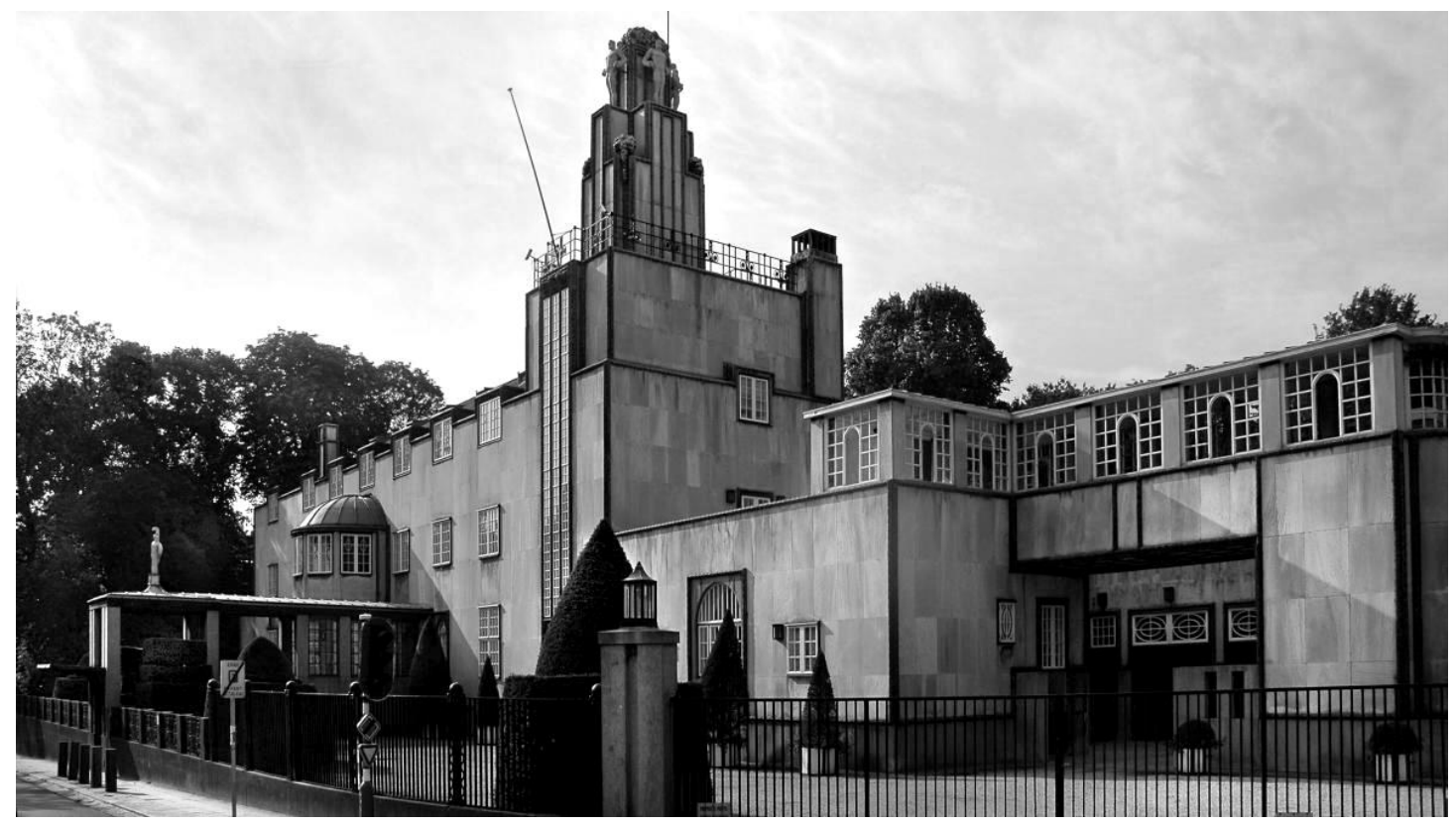

Figura 1 - Palais Stoclet, Josef Hoffmann (1911), Vista geral. Autor desconhecido. 

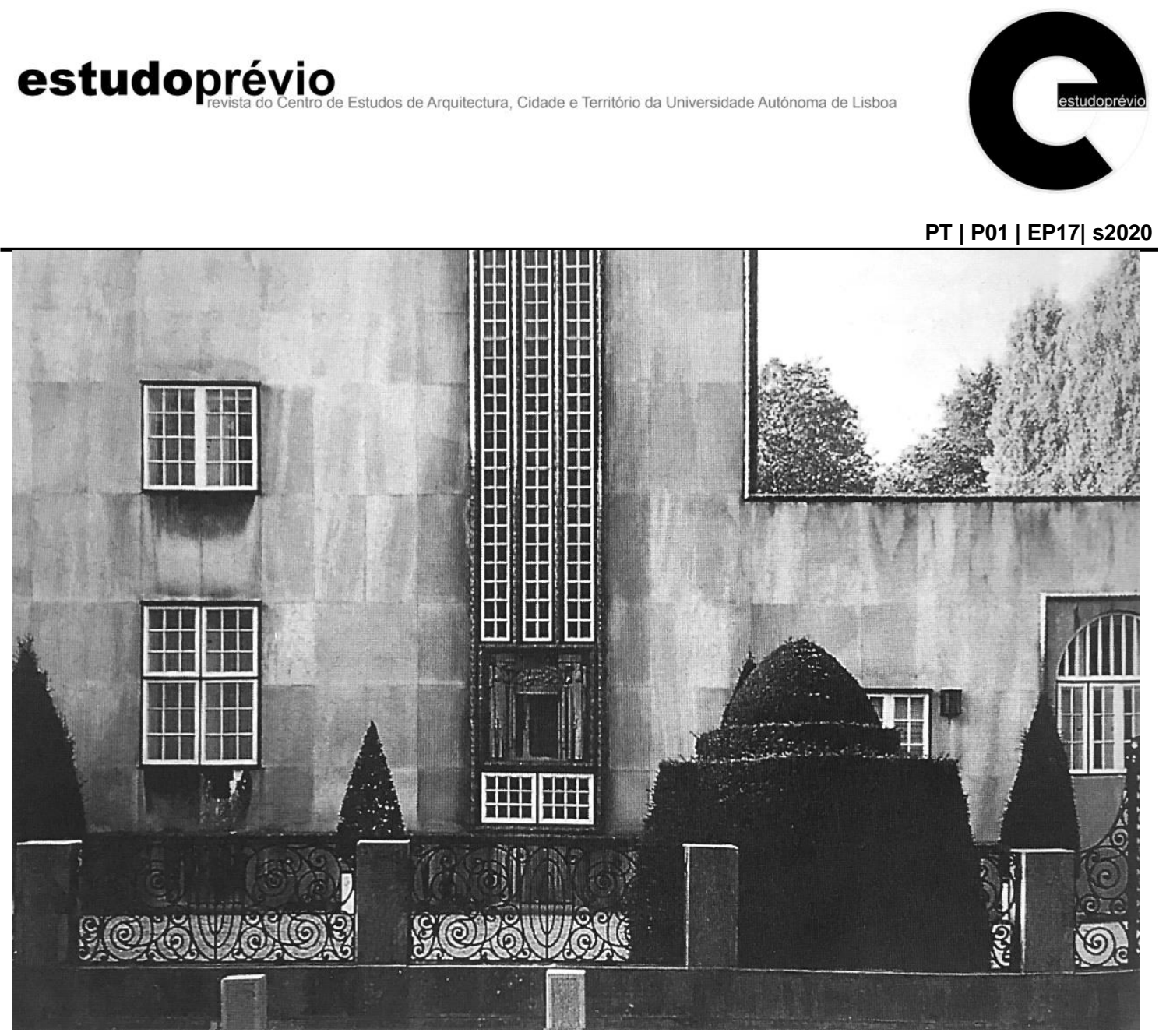

Figura 2 - Palais Stoclet, Josef Hoffmann (1911), detalhe da fachada. Autor desconhecido. Fonte: Leatherbarrow, 2007: 94.

O certo é que esta abordagem parece inclusive estar mais próxima das ideias preconizadas por Gottfried Semper do que no caso do Postal Savings Bank, sobretudo se atendermos às suas palavras em 'Der Stil'. No capítulo dedicado à arte têxtil, Semper afirma que "a anulação da realidade, do material, é necessária quando se considera que a forma deve aparecer como um símbolo, carregado de significado e, simultaneamente, como uma criação autónoma do Homem. Devemos fazer esquecer os meios utilizados para se alcançar o efeito artístico desejado" (Semper, 2014: 309). Percebemos então porque motivo Hoffmann procura ocultar a espessura e a fixação do mármore através de um elemento ornamental que remete para uma costura de tapeçaria. Deste modo estabelece uma analogia com o mundo têxtil, que segundo Semper estaria na origem da própria arquitetura (Semper, 2014: 298). Também podemos verificar que os vãos se encontram perfeitamente alinhados pela face exterior da fachada, para evitar qualquer ideia de profundidade, e estão demarcados pelo mesmo ornamento, que esconde assim o encontro das placas de mármore também neste ponto. Hoffmann quer contar-nos que aquelas paredes exteriores não têm espessura, são apenas elementos de tapeçaria suspensos. A técnica é apenas um meio para alcançar o efeito artístico e, como tal, não assume qualquer expressão. O mesmo acontece no interior, no qual os elementos construtivos como pilares, vigas ou arcos são revestidos por placas finas de pedra. O efeito plano destas superfícies é reforçado pelas pinturas de Gusav Klimt (Viena, 1862 - Viena, 1918), amigo de Hoffmann e uma das figuras mais influentes da secessão vienense (Fanelli, 1999: 95), (Figura 3). 


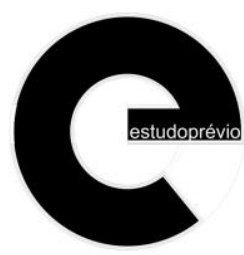

PT | P01 | EP17| s2020

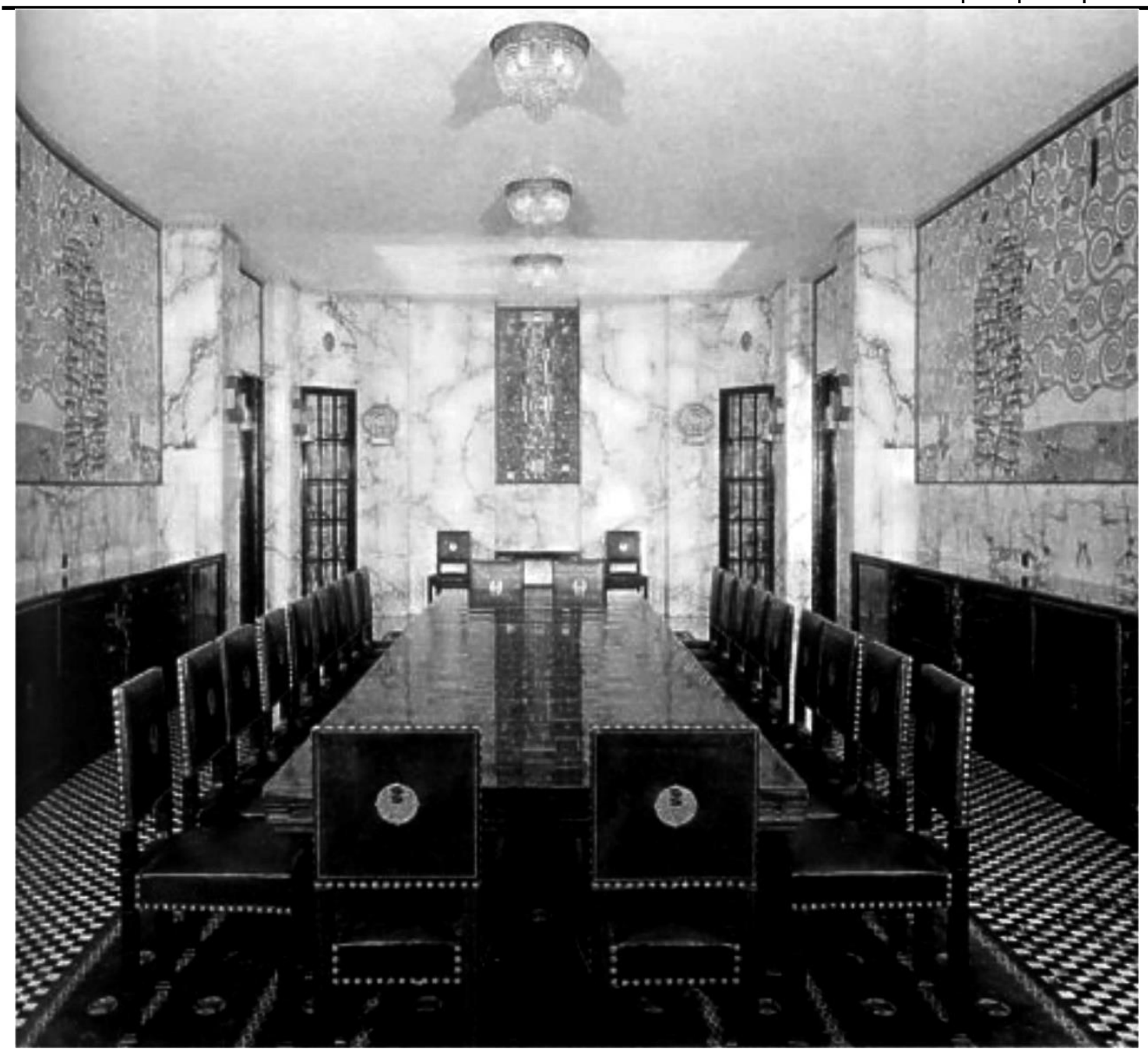

Figura 3 - Palais Stoclet, Josef Hoffmann (1911), Vista interior. Autor desconhecido.

Giovanni Fanelli e Roberto Gargiani afirmam que os escritos de Semper em Der Stil são uma apologia da anulação da realidade e da ocultação dos materiais através do ato de emascarar. Contudo, no plano teórico para Semper este ato de emascarar implicaria sempre o domínio da técnica, o que terá levado a "aparentes contradições entre a vocação do «Nutzstil» enquanto modo de aplicação das tecnologias modernas ou enquanto manifestação concreta do ideal semperiano que propunha a transfiguração simbólica da realidade construtiva" (Fanelli, 1999: 66). É precisamente este ponto que nos permite entender melhor as diferenças de interpretação entre Hoffmann, que procurava esta transfiguração simbólica da realidade construtiva e Wagner, que estava definitivamente empenhado na definição de um estilo moderno que teria de surgir através dos novos materiais, das novas tecnologias construtivas e dos novos sistemas construtivos. Uma vez mais podemos deduzir que se trata de atribuir a primazia à expressão simbólica da forma artística, no caso de Hoffmann, ou de atribuir a primazia à expressão construtiva da forma artística, no caso de Wagner. 
Em abril de 1894, dois anos de publicar pela primeira vez "Modern Arkitectur" Wagner é anunciado como arquiteto do Stadtbahn, o novo sistema ferroviário da cidade de Viena. Durante seis anos Wagner desenvolve o projeto para mais de quarenta estações de metro, pontes ou viadutos e é confrontado com restrições de ordem económica e exigências de ordem funcional (Mallgrave, 1988: 27). A componente infraestrutural deste projeto de grande escala acabou por marcar decisivamente a obra posterior de Wagner aproximando-o do campo da engenharia e dos novos sistemas estruturais em ferro e betão armado.

\begin{abstract}
"As considerações wagnerianas sobre o «platternverkleidung» com fixação metálica exposta são formuladas no momento em que Wagner se encontra a desenvolver os projetos para o metro de Viena e se vê confrontado, a partir de 1894, com problemas técnicos e formais na relação entre a construção murária e as estruturas metálicas. Para essa articulação, a fixação através de elementos metálicos assume uma importância simbólica decisiva." (Fanelli, 1999: 74)
\end{abstract}

De facto, é nas estações de metro de Karlplatz (Viena, 1898) que em 1898 Wagner leva a cabo as primeiras investigações sobre o potencial expressivo das fixações metálicas aparentes. Trata-se das únicas obras de Wagner construídas em estrutura metálica e existe uma clara intenção de revelar a função estática do elegante esqueleto que se manifesta pelo exterior em oposição às finas placas de mármore com apenas dois centímetros que preenchem o vazio deixado entre a os elementos verticais (Figuras 4, 5 e 6). O revestimento não é utilizado como meio de ocultar a materialidade nem o ritmo da estrutura, bem pelo contrário, podemos ler a sua própria condição não estrutural. Mas o mais significativo é sem dúvida o modo como Wagner pretende expressar essa condição através dos elementos metálicos circulares colocados na parte superior do edifício que revelam o modo de fixação das placas de mármore, como se estivessem suspensas desde a parte superior, e também a materialidade da estrutura interior. Como se a própria estrutura tivesse elementos salientes que agarrassem a placa de revestimento. Embora seja ainda evidente a forte presença de ornamento decorativo aplicado pelo exterior, à semelhança de outros projetos como a famosa Majolikahaus (Viena, 1899), (Figuras 7 e 08), o certo é que nestes edifícios esse ornamento gráfico de influência têxtil é reservado apenas à parte superior, precisamente onde encontramos os elementos metálicos de fixação. A forma artística já aparece diretamente relacionada com a construção e a lógica estrutural, antecipando assim o crescente valor expressivo da construção nas obras sucessivas de Wagner (Figura 9).
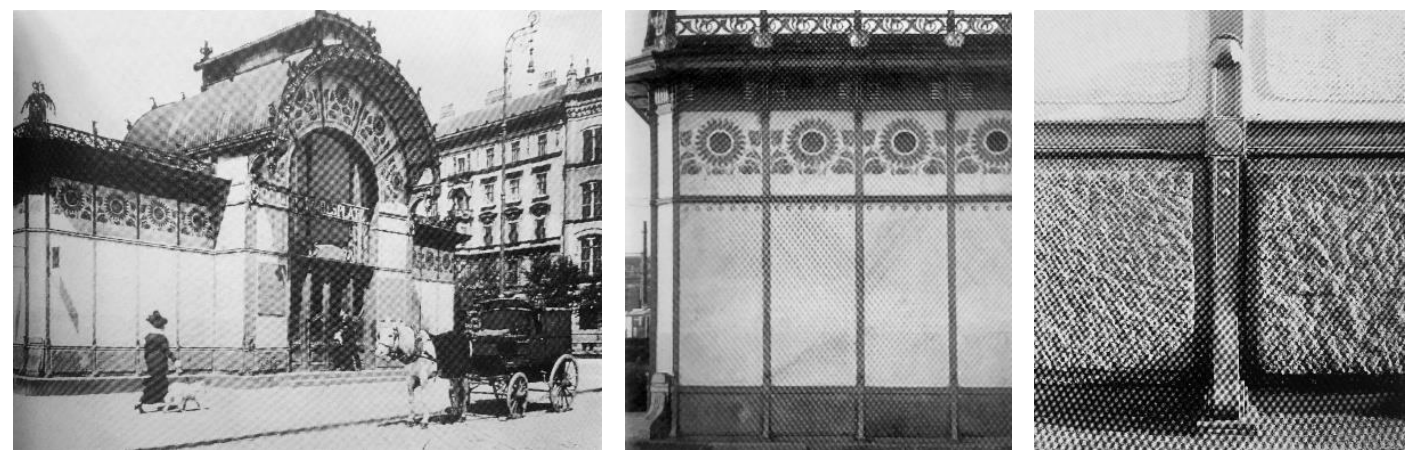

Figuras 4 a 6 - Estação Karlplatz, Otto Wagner (1899). Figura 4 - Vista geral. Fotografia de época. Figuras 5 e 6 - Detalhes. R. Gargiani. Fonte: Fanelli, 1999: 119. 

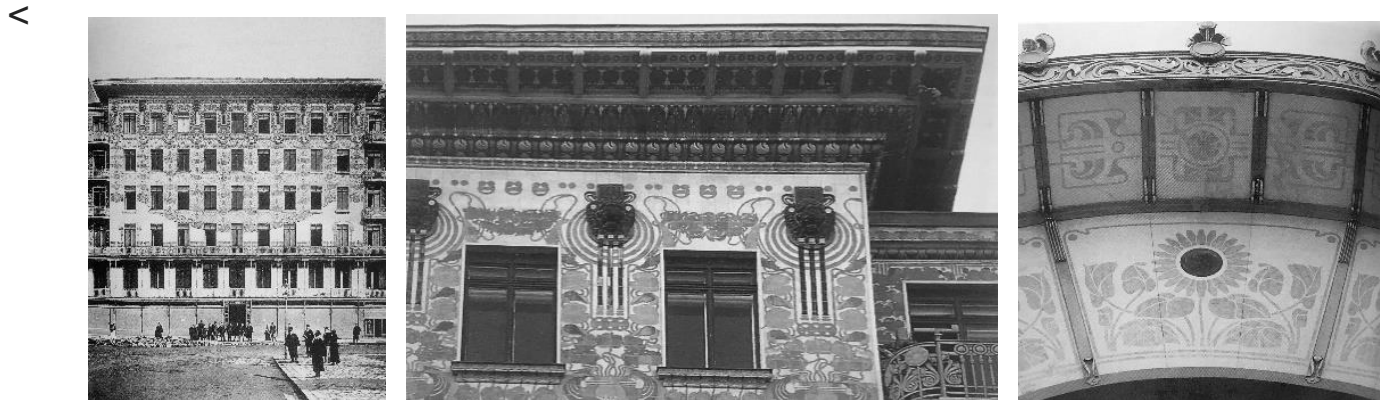

Figuras 7 e 8 - Edifício Majolikahaus, Otto Wagner (1898). Figura 7- Vista geral. Fotografia de época. Fonte: Fanelli, 1999: 109. Figura 8 - Detalhe da fachada. Autor desconhecido. Fonte: Leatherbarrow, 2007: 100. Figura 9 - Estação Karlplatz, Otto Wagner (1899), detalhe. R. Gargiani. Fonte: Fanelli, 1999: 120.

Nos anos seguintes Wagner explora inúmeras variações sobre este detalhe construtivo e inclusive começa a adaptar a solução a outro tipo de estruturas. "Os primeiros exemplos de placas de mármore ancoradas sobre estruturas murárias de tijolo e pedra aparecem nos esquissos de estudo para a galeria de arte moderna (Viena, 1899)" (Fanelli, 1999: 83). O facto de o elemento de fixação do revestimento ser metálico e a estrutura ser de outro material torna mais ambígua a relação entre ambos e parece que a construção prevalece sobre a própria estrutura, no entanto não há dúvida que o simbolismo que Wagner procura atribuir à fachada através deste detalhe tem uma estreita relação com a lógica tectónica.
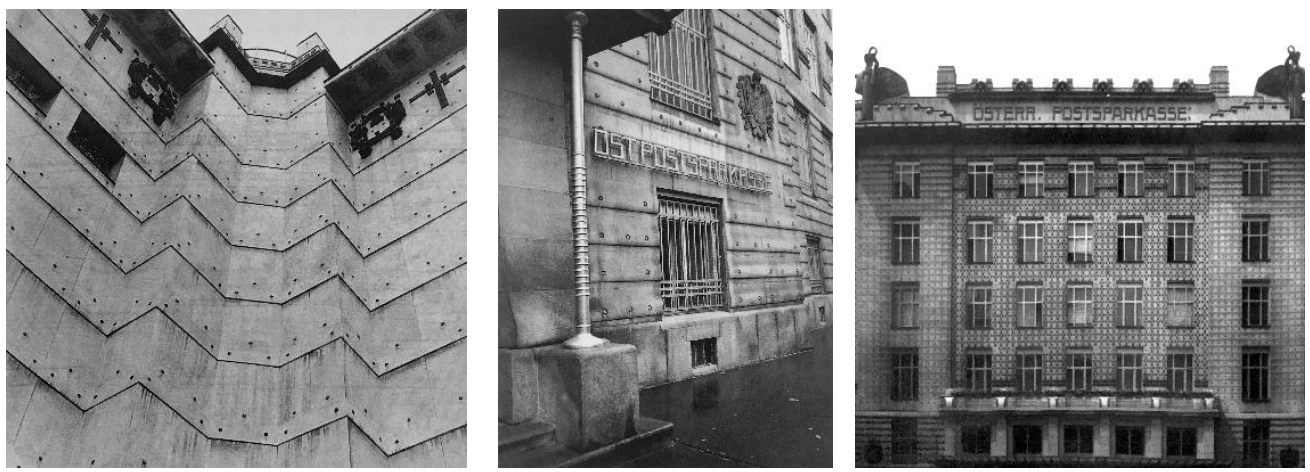

Figura 10 - Igreja St. Leopold Am Steinhof, Otto Wagner (1904), detalhe da fachada. Charles H. Tashima. Fonte: Leatherbarrow, 2007: 101. Figuras 11 e 12 - Postal Savings Bank, Otto Wagner (1904-1906, 1910-1912). Figura 11 - Detalhe da fachada. Charles H. Tashima. (Leatherbarrow, 2007: 102). Figura 12 - Vista geral. Autor desconhecido. Fonte: Fanelli, 1999: capa.

O culminar desta investigação e refinamento acontece a partir de 1903, precisamente nos dois edifícios de carácter monumental que Wagner desenvolve na mesma altura para a cidade de Viena, a igreja de St. Leopold Am Steinhof (Viena, 1904) a sede do Postal Savings Bank (Figura 10), construído em duas fases distintas (Viena,19041906 e 1910-1912), (Figuras11 e 12). Este último é o mais paradigmático não só pela linguagem complexa e hierárquica que Wagner utiliza a partir desta solução construtiva 
mas também porque se trata de um edifício de escala urbana situado em frente ao grande eixo da Ringerstrasse, justamente onde se encontram vários edifícios projetados por Gottfried Semper e em particular o Teatro Nacional que Wagner utilizara de forma crítica como exemplo de uma maneira de construir equivocada (Wagner, 1993: 84). Neste projeto Wagner recorre a uma estrutura portante de tijolo, no entanto aplica a solução de fixação metálica a todos os revestimentos, tanto de pedra como de metal, tanto no exterior como no interior (Figuras 13, 14 e 15).
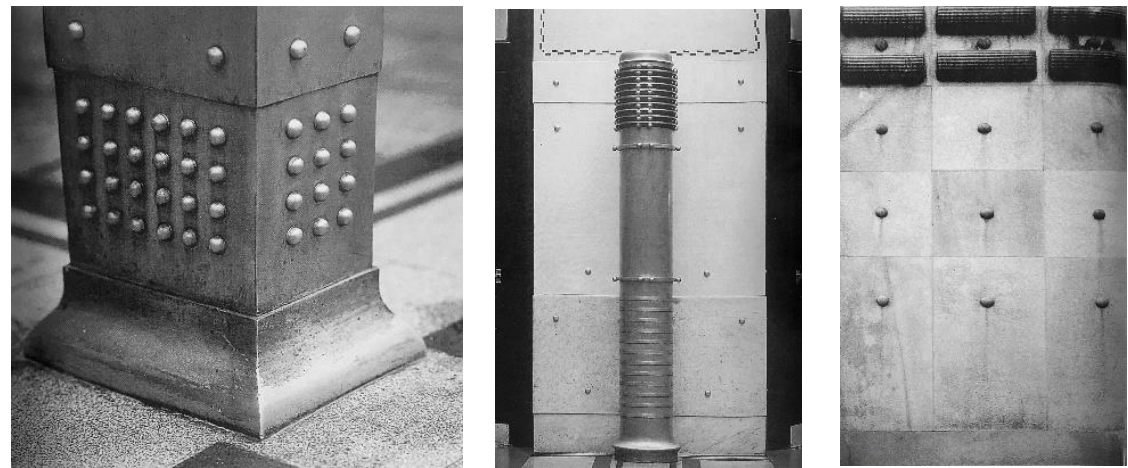

Figuras 13 a 15 - Postal Savings Bank, Otto Wagner (1904-1906, 1910-1912), detalhes interiores. R. Gargiani. Fonte: Fanelli, 1999: 133, 132 e 130.

No que concerne ao tratamento da fachada exterior, à semelhança do que acontece com Hoffmann também Wagner pretende transmitir uma ideia de ligeireza e pretende celebrar a reduzida espessura do revestimento exterior, o que coincide de forma genérica com as reflexões de Semper, contudo a sua interpretação é muito distinta. Enquanto Hoffmann trabalha essa ideia ocultando a espessura, Wagner aproveita as esquinas para encostar o revestimento de ambas as fachadas e permitir que a espessura real seja legível nesse momento de encontro:

"o embasamento de pedra é de estilo clássico, mas nas esquinas podemos observar uma certa ligeireza moderna que expõe a artificialidade deste gesto. Esta prática oculta e relva ao mesmo tempo, é uma forma de construção que se distingue de si mesma, tendo como resultado uma arte da construção idealizada ou desnaturalizada" (Leatherbarrow, 2007:103), (Figura 16).

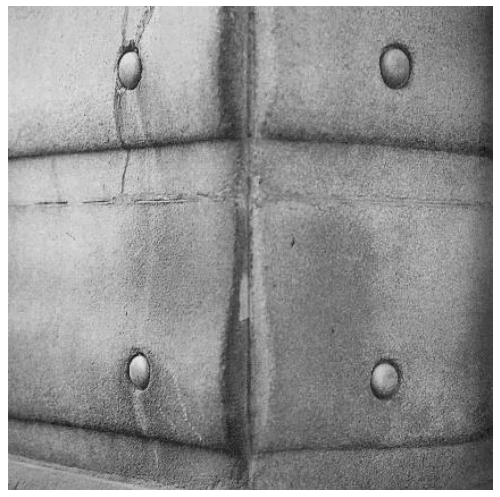

Figura 16 - Postal Savings Bank, Otto Wagner (1904-1906, 1910-1912), detalhe exterior. R. Gargiani. (Fanelli, 1999: 134). 
Podemos por isso perceber que o embasamento é feito com placas de granito de 6 a 9 centímetros de espessura enquanto a parte superior utiliza placas de mármore de Ratchinges com apenas 2 centímetros de espessura reforçando a ideia previamente assinalada por Wagner de que ao reduzir a espessura do revestimento exterior poderíamos utilizar um material mais nobre (Figuras 17 e 18). Esta lógica hierárquica visível nos materiais exteriores aplica-se igualmente ao detalhe da fixação. Wagner pretende dar maior carácter simbólico à fachada principal que se relaciona com um dos eixos principais da cidade e revela que "as placas de mármore estão perfuradas no centro e fixas ao muro (...) Na parte central da fachada, visível desde a Ringerstrasse, as placas estão decoradas com aplicações de alumínio" (Fanelli, 1999: 85). A ancoragem das placas de revestimento exterior volta a repetir o mesmo tipo de detalhe, neste caso específico através de varões de ferro com cerca de 20 centímetros cravados na parede estrutural que atravessam o painel de revestimento até ao exterior. Estes elementos são revestidos no primeiro tramo interior com um tratamento de chumbo e no remate exterior com a aplicação de uma cabeça de rebite idêntica ao das estruturas metálicas que podemos ver no interior, aqui revestidas com alumínio opaco (Figuras 19 e 20).
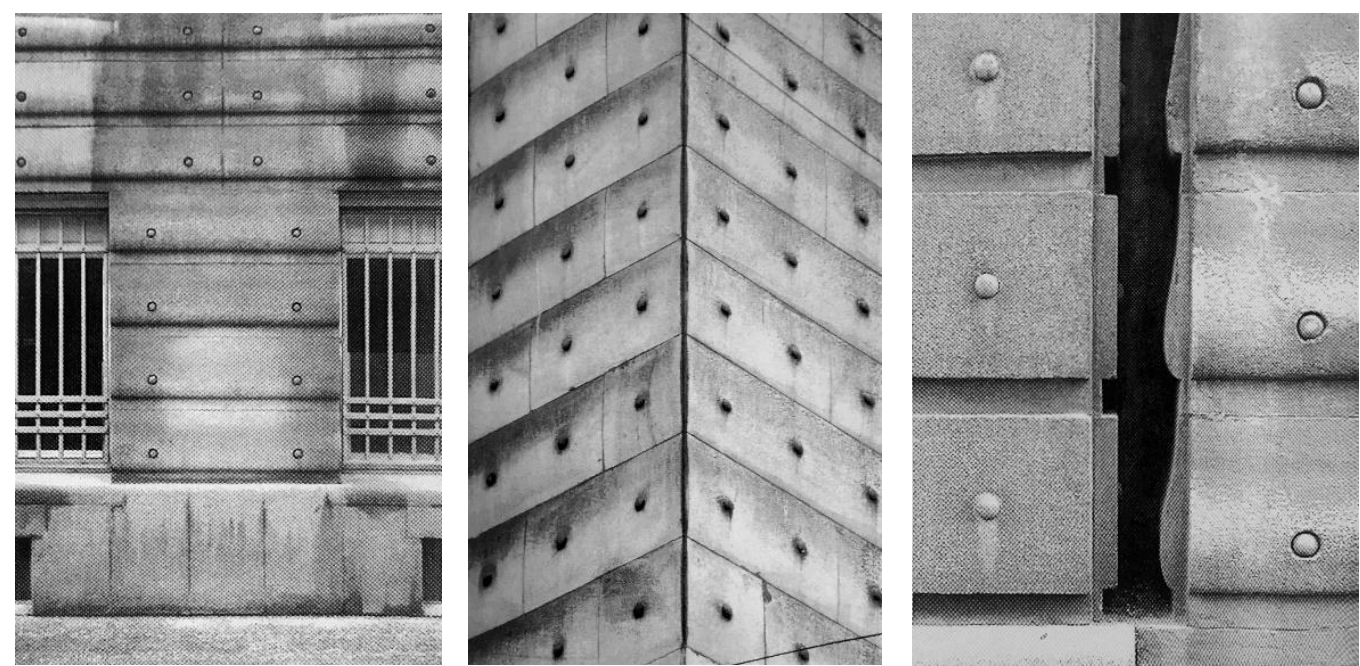

Figuras 17 a 19 - Postal Savings Bank, Otto Wagner (1904-1906, 1910-1912), detalhes exteriores. R. Gargiani. Fonte: Fanelli, 1999: 128, 131, e 128).

Conforme assinala Keneth Frampton, existe uma vontade clara por parte de Wagner em transmitir a verdade construtiva do edifício para os seus utilizadores:

"somos levados a pensar que essas peças de metal suportam o revestimento de pedra e, como tal, são essenciais para o revestimento do edifício. Na verdade, penso que esses elementos não acrescentam muito do ponto vista técnico, mas é a expressão de um desejo por parte de Wagner para que a estrutura, tanto na grande escala como no detalhe desses pequenos elementos, seja toda parte do mesmo. A estrutura é aquilo que une o edifício em todo o seu conjunto." (Frampton, 2020)

Efetivamente estes elementos não são responsáveis por ancorar de forma definitiva o revestimento do edifício, contudo são parte fundamental no processo de execução construtiva. É como se Wagner quisesse deixar a cimbre de madeira aparente após a execução de um arco estrutural em tijolo. Depois do projeto para as estações de metro 


\section{estudoprévio}

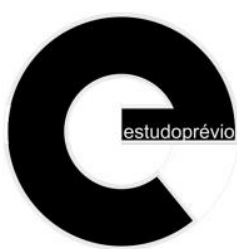

PT | P01 | EP17| s2020

de Viena a consciência económica de Wagner tornou-se muito presente e isso refletiase na racionalização dos materiais, mas também na racionalização dos tempos de execução. Este sistema construtivo permitia que as placas de mármore fossem aplicadas de forma muito mais rápida já que a fixação metálica garantia o seu posicionamento final durante o longo tempo de secagem das argamassas (Fanelli, 1999: 85). A forma artística é uma consequência direta da forma construtiva e assinala o simbolismo presente no ato físico da sua manufatura. Wagner consegue expandir o conceito do simbolismo cósmico e rítmico defendido por Semper e conciliá-lo com a lógica estrutural e construtiva presente nas teorias de Karl Bötticher. Segundo Frampton

"o Postal Savings Bank é um edifício chave na carreira de Wagner. Poderíamos dizer que Wagner está descontente pelo facto de Semper ver o ornamento como uma questão rítmica ou uma escrita cósmica, porque isso não é profundamente estrutural. Wagner quer que o ornamento seja profundamente estrutural e isso é uma diferença muito sensível, mas muito importante." (Frampton, 2020).

Esta lógica construtiva pode ser encontrada no resto do edifício, inclusive nas estruturas metálicas e revestimentos de vidro presentes no espaço principal interior, mas o aspeto mais relevante aqui é precisamente o facto de este detalhe construtivo de Wagner através da sua microescala ser o responsável pelo caracter expressivo e monumental que observamos no edifício. É também através dele que identificamos, à semelhança do que acontece nos escritos de Wagner, um reconhecimento e uma crítica à figura de Gottfried Semper, o arquiteto que mais influenciou o seu percurso enquanto arquiteto e teórico.

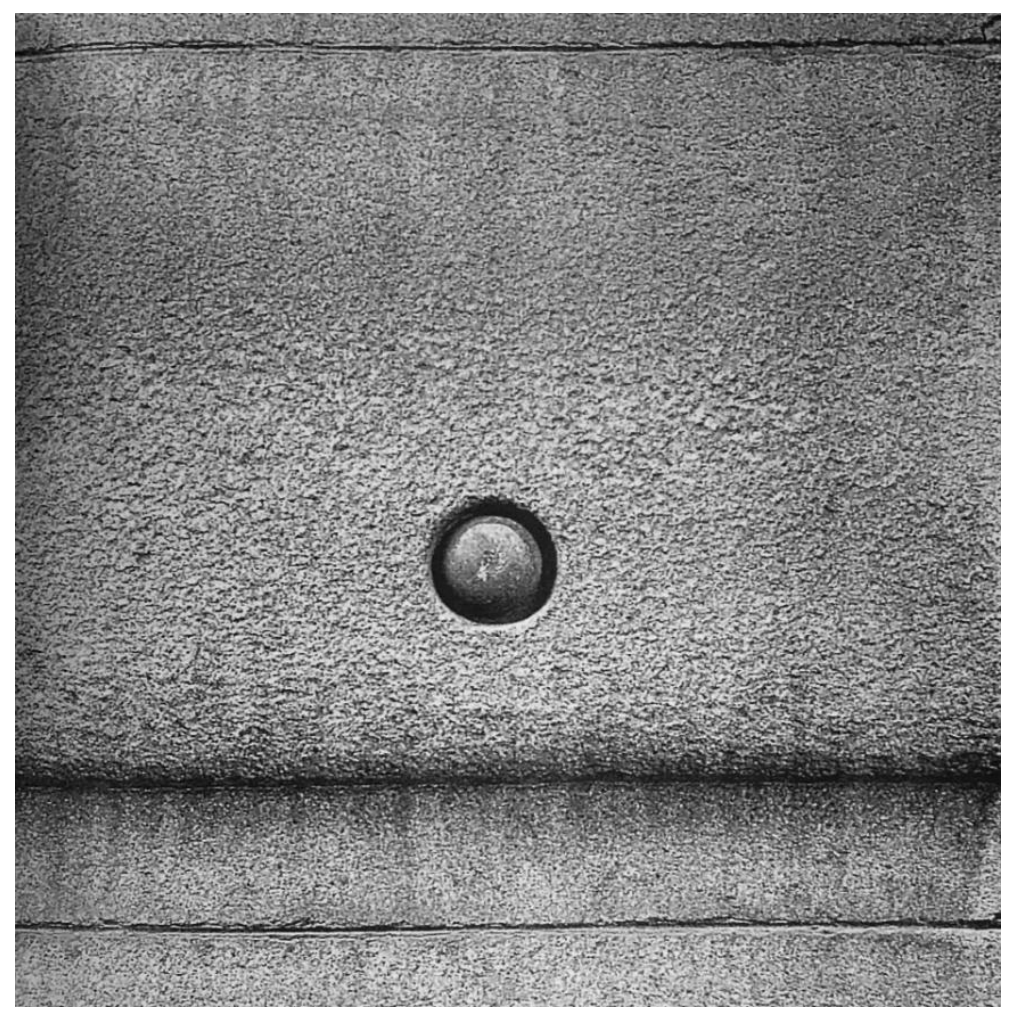

Figura 20 - Postal Savings Bank, Otto Wagner (1904-1906, 1910-1912), detalhe exterior. R. 
Gargiani. Fonte: Fanelli, 1999: 129.

\section{Conclusão}

Não há dúvida quanto ao papel fundamental de Otto Wagner no rumo da arquitetura moderna. A sua atitude propositiva na utilização racional das novas tecnologias, aproveitando todo o seu potencial expressivo, contribuíam definitivamente para um corte com uma arquitetura eclética, de estilo neoclássico, e para a definição de um novo estilo a que chamou moderno. Alguns anos antes Karl Bötticher tinha antecipado este cenário ao afirmar que

"ninguém percebeu que a origem de todos os estilos específicos está no efeito que um novo princípio estrutural cria a partir do material e apenas isso dá origem à formação de novos sistemas de cobertura espacial e consequentemente ao surgimento de um novo mundo de formas artísticas" (Bötticher, 1852).

Wagner demonstrou estar consciente deste postulado quando afirmou que as formas artísticas deveriam nascer a partir da construção, negando assim a ideia da máscara como ocultação da realidade construtiva, indiciada de modo um pouco ambíguo parte de Gottfried Semper (Wagner, 1993: 81). A máscara também está presente em Wagner e é inquestionável a sua estreita relação e continuidade com as teorias de Semper, mas neste ponto a divergência parece latente.

Tanto o Palais Stoclet, de Hoffmann, quanto o Postal Savings Bank, de Wagner, são herdeiros do legado de Semper. A diferença, contudo, está nos detalhes. São eles que ocultam ou revelam o rosto por trás da máscara, o osso por trás da pele. Hoffmann utiliza a forma artística para ocultar, Wagner para revelar. Nesse sentido poderíamos concluir que Hoffmann está mais próximo da materialização das ideias de Semper. Isto porque o detalhe construtivo que Wagner desenvolve ao longo de vários anos e aplica de maneira tão radical a todos os elementos no Postal Savings Bank é uma manifestação evidente dessa divergência. Trata-se de uma diferença de interpretação subtil que na verdade é muito significativa e coloca a o problema num patamar quase filosófico e ontológico. Onde está a verdade arquitetónica? Qual a origem das formas tectónicas?

No seu texto de 1898 intitulado "Das Prinzip der Bekleidung" (O princípio do revestimento) o arquiteto Adolf Loos enumera quase ponto por ponto as teorias preconizadas por Gottfried Semper acerca da arte têxtil e da origem da arquitetura: "No princípio era o revestimento". Loos afirma com grande clareza que a primeira tarefa do arquiteto é escolher o revestimento e só depois conceber a estrutura que o suporta. Esta perspetiva afasta-se diametralmente dos princípios construtivos e estruturais defendidos por Laugier ou Viollet-le-Duc, que idealizavam a estrutura da cabana primitiva como o gesto fundacional da disciplina. Esta oposição entre a primazia pela forma nuclear da estrutura portante ou pela forma artística do revestimento simbólico remete para o profundo debate preconizado entre Karl Bötticher e Gottfried Semper acerca da formação dos templos helénicos (Hermann, 1984: 139).

No quarto capítulo de "Modern Arkitectur" Otto Wagner faz uso explícito dos conceitos forma núcleo e forma artística, formulados por Karl Bötticher no livro "Die Tektonik der hellenen" (A tectónica dos helénicos) e apresenta uma perspetiva com claras 
PT | P01 | EP17| s2020

afinidades intelectuais. A ausência de qualquer alusão a Bötticher por parte de Wagner é curiosa e não existe uma justificação objetiva embora este facto talvez se deva às discordâncias protagonizadas com Semper precisamente sobre este tema. Bötticher defendeu que a arquitetura dependia de dois conceitos: a forma núcleo, que representaria a estrutura mecânica, e a forma artística, que revelaria a função estática do edifício através da ornamentação. Ambos deveriam nascer em simultâneo e de forma orgânica. Poucos anos mais tarde Semper adaptaria a ideia da forma artística de Bötticher à sua teoria do revestimento atribuindo primazia ao ato simbólico de vestir o edifício e associando esse gesto à origem das culturas primitivas, às pinturas tribais e à presença cósmica do Homem no mundo.

Não podemos afirmar com total certeza que Wagner tenha lido o livro de Bötticher apesar de ser muito provável que tal tenha acontecido durante a breve passagem por Berlim enquanto prosseguia com os seus estudos académicos (Mallgrave, 1988: 4). O certo é que as divergências que identificamos entre o pensamento de Wagner e Semper são as mesmas que aproximam Wagner e Bötticher. Quase poderíamos deduzir que a investigação acerca do detalhe metálico de fixação do revestimento é uma tentativa de conciliação conceptual entre ambos. O ornamento simbólico nasce de uma necessidade estrutural e desse modo atribuí valor cultural ao gesto construtivo. Através desse detalhe Wagner clarifica a articulação entre a "forma núcleo" e a "forma artística", dois conceitos que continuam a ter um enorme potencial enquanto ferramenta operativa para a análise e conceção da arquitetura. A sua articulação, interdependência, confronto ou negação está presente nas arquiteturas construídas desde o século XX e existe uma necessidade de aclarar o alcance real da sua definição.

\section{Agradecimentos}

O presente artigo surge no âmbito de uma investigação para doutoramento desenvolvida na Escuela Técnica Superior de Arquitectura de Madrid (ETSAM), sob a orientação científica do Professor Alberto Campo Baeza, financiada através de uma Bolsa de Doutoramento da Fundação para a Ciência e Tecnologia (SFRH/BD/104989/2014).

\section{Bibliografia}

BREITSCHMID, Markus - Can architectural art-form be designed out of construction? Virginia: Architecture edition, 2004. ISBN: 978-0-9702-8208-8

BÖTTICHER, Karl - The principles of the Hellenic and Germanic ways of building with regard to their application to our present way of building (1852). In Foged, Isak Worre; Hvejsel, Marie Frier - Reader. Tectonics in Architecture. Aalborg: Aalborg University Press, 2018. ISBN/ISSN: 978-87-7112-671-6

BÖTTICHER, Karl - Tectonics - Theory of Raiment. (1844) In Oechslin, Werner - Otto Wagner, Adolf Loos, and the road to Modern Architecture. New York: Cambridge University Press, 2002. ISBN: 978-0-521-62346-9

FANNELLI, Giovanni; GARGIANI, Roberto - El Principio del Revestimiento: 
PT | P01 | EP17| s2020

Prolegómenos a una história de la arquitectura contemporánea. Madrid: Akal, 1999. ISBN: 84-460-1180-8

FRAMPTON, Kenneth - Entrevista concedida a João Quintela no âmbito de uma investigação de doutoramento. A publicar (não acessível). Porto: 2020

FRAMPTON, Kenneth - The Structure and Symbolism of the Art Nouveau 1851-1914. Tokyo: 1981. ISBN/ISSN:

FRAMPTON, Kenneth - Studies in Tectonic Culture: The Poetics of Construction in Nineteenth and Twentieth Century Architecture. Cambridge: MA: MIT Press, 1995. ISBN: 84-460-1187-5

FRAMPTON, Kenneth - História Crítica de la Arquitectura Moderna. Barelona: Gustavo Gili, 2009. ISBN: 9788425216282

HERRMANN, Wolfgang - Gottfried Semper: In search of Architecture. USA: The MIT Press, 1984. ISBN: 0-262-08144-X

LEATHERBARROW, David; MOSTAFAVI, Mohsen - La superficie de la Arquitectura. Madrid: Ediciones Akal, 2007. ISBN: 978-84-460-2312-8

LOOS, Adolf - Dicho en el vacío (1897-1900). Valencia: Colégio Oficial de Aparejadores y Arquitectos Técnicos de Murcia, 2003. ISBN: 84-505-0132-6

LOOS, Adolf - Ornamento e Crime. Lisboa: Edições Cotovia, 2004. ISBN:

MALLGRAVE, Harry Francis - Modern Architecture, Otto Wagner: A guidebook for his students to this field of art. Santa Monica: The Getty Center for the History of Art and the Humanities, 1988. ISBN/ISSN: 0226869385

MALLGRAVE, Harry Francis - Otto Wagner: Reflections on the Raiment of Modernity. Santa Monica: The Getty Center for the History of Art and the Humanities, 1993. ISBN/ISSN: 0-89236-258-8

OECHSLIN, Werner - Otto Wagner. Reflections on the Raiment of Modernity. Canada: Getty Publications, 1993. - The Evolutionary Way to Modern Architecture: The Paradigm of Stilhülse un Kern. ISBN:

OECHSLIN, Werner - Otto Wagner, Adolf Loos, and the road to Modern architecture. New York: Cambridge University Press, 2002. ISBN: 978-0-521-62346-9

SEKLER, Eduard - Structure in Art and Science. New York: George Braziller, 1965. Structure, Construction \& Tectonics. ISBN:

SEKLER, Eduard - Essays in the History of Architecture presented to Rudolf Wittkower. Londen: Phaidon, 1967. - The Stoclet House by Josef Hoffmann. ISBN:

SEMPER,Gottfried - The Four Elements of Architecture and Other Writings. Cambridge: Cambridge University Press, 1989. ISBN:

SEMPER, Gotfried - Escritos fundamentales in ARMESTO António - Escritos Fundamentales de Gottfried Semper. Barcelona: Fundación Arquia, 2014. ISBN/ISSN: 978-84-940343-2-9

WAGNER, Otto - La Arquitectura de nuestro tiempo. Madrid: El Croquis Editorial, 1993. ISBN: 84-88386-02-8

\section{Biografia:}

Licenciado pela Universidade Autónoma de Lisboa e Politécnico di Milano. Cofundador do Atelier JQTS, com Tim Simon. Foi curador do Pavilhão KAIROS com Tim Simon e Fabrícia Valente. Entre 2012 e 2017 foi professor assistente na UD Campo Baeza na ETSAM e desde 2017 leciona na UAL. Desenvolve a tese de doutoramento na Escuela Técnica Superior de Arquitectura de Madrid. 


\section{estudoprévio}

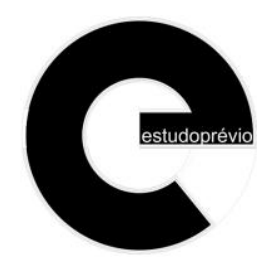

PT | P01 | EP17| s2020

* Este artigo é parte de uma investigação de Doutoramento desenvolvida na Escuela Técnica Superior de Arquitectura de Madrid (ETSAM), sob a orientação cinetífica do Professor Alberto Campo Baeza, financiada atrvés de uma bolsa de doutoramento da Fundação para a Ciência e Tecnologia (FCT). 